\title{
STRUCTURAL CHARACTERISTICS AND DISTRIBUTION OF LIGNIN IN EUCALYPTUS GLOBULUS PULPS OBTAINED BY A COMBINED AUTOHYDROLSIS/ALKALINE EXTRACTION PROCESS FOR ENZYMATIC SACCHARIFICATION OF CELLULOSE
}

\author{
FABIO ARAYAA,B, EDUARDO TRONCOSOB, REGIS TEIXEIRA MENDONCCAB, C, JUANITA \\ FREERA,B, JORGE RENCORETD AND JOSÉ CARLOS DEL RÍOD
}

\author{
${ }^{a}$ Facultad de Ciencias Químicas, Universidad de Concepción, Casilla 160-C, Concepción, Chile. \\ ${ }^{b}$ Centro de Biotecnología, Universidad de Concepción, Casilla 160-C, Concepción, Chile. \\ 'Facultad de Ciencias Forestales, Universidad de Concepción, Casilla 160-C, Concepción, Chile. \\ ${ }^{d}$ Instituto de Recursos Naturales y Agrobiología de Sevilla, España
}

\begin{abstract}
Eucalyptus globulus wood chips were subjected to autohydrolysis pretreatment at $175^{\circ} \mathrm{C}$ at three different residence times. Part of the recovered solids were submitted to alkaline extraction with $\mathrm{NaOH}$ solution to remove leachable lignin. The chemical composition of the fibrous material was analyzed by HPLC, PyGCMS and 2D-NMR HSQC, while morphological changes were evaluated by SEM and LSCM. The pretreated materials were hydrolyzed with cellulases at a substrate loading of $10 \%(\mathrm{w} / \mathrm{v})$ for up to $72 \mathrm{~h}$. Glucose yields (based on dry wood) obtained in the enzymatic hydrolysis ranged between $38 \%$ and $65 \%$, depending on reaction time in the autohydrolysis pretreatment. After the alkaline extraction, no significant change was observed in the yields in the enzymatic hydrolysis at $72 \mathrm{~h}$, but at the lower severities, the initial rates of saccharification increased. The main effect of the hydrothermal pretreatment was removal of hemicelluloses, resulting in enriched cellulose pulps. SEM and LSCM images of the hydrothermal pretreated samples showed a disruption of the fiber surface, mainly in those samples obtained at the higher severity. Py-GC/MS and HSQC analysis showed that no major changes in the lignin structure occurred in the samples obtained by autohydrolysis and further alkaline extraction. By autohydrolysis at the higher severity $(\mathrm{So}=4.02)$, the lateral chains in lignin were cleaved and the formation of lignin droplets was observed. Hemicelluloses removal and lignin redeposition as droplets in certain regions of the fiber surface was associated with the higher accessibility of cellulose and the yield increase of the enzymatic hydrolysis.
\end{abstract}

Keywords: Eucalyptus globulus; autohydrolysis; alkaline extraction; lignin; enzymatic hydrolysis.

\section{INTRODUCTION}

Enzymatic hydrolysis of cellulose is one important step for bioethanol production from lignocellulosic biomass (LCB) ${ }_{1 ; 2 ; 3}$. Conversion of LCB particularly wood, to ethanol is difficult owing to the ultrastructure's resistance to breakdown and also, the presence of lignin and hemicelluloses, represent a barrier to the accessibility of the enzymes to cellulose, resulting in the recalcitrance to biochemical conversion to sugars, making necessary a pretreatment for fractionation and disaggregation of LCB components 4,5 . Pretreatments used included physical, chemical and thermal methods, and also their combinations ${ }^{6,7}$. Depending on the feedstock and pretreatment conditions, several properties of the biomass are altered and affect, at different extent, the recalcitrance of the pretreated material. Different factors have been considered affecting the enzymatic hydrolysis yield, among them are the lignin content and structure; the content of hemicelluloses, acetyl and uronic groups; the cellulose cristallinity and degree of polymerization, specific surface area, pore volume and particle size are also mentioned ${ }^{8,9,10}$. Once the structure of the biomass is disrupted, the carbohydrates can be converted to monomeric sugars that are suitable for fermentation ${ }^{11}$. The identification and quantification of the main factors that can hinder or enhance the production of bioethanol from LCB is fundamental and subject of several studies.

In previous studies, it was observed that the lignin content is correlated with cellulose accessibility, being a barrier to the enzymatic hydrolysis, by blocking the accessibility of the enzymes to the cellulose microfibrils ${ }^{12}$ 13. Lignin also tends to irreversibly bind the enzymes through hydrophobic interactions causing a loss in cellulases activities ${ }^{14,15,16}$.In addition, during the pretreatment step lignin suffer changes in its structure and the effects on the enzymatic hydrolysis of cellulose are not completely understood ${ }^{17,18}$ For instance, the chemical removal of lignin after dilute acid pretreatment reduced the cellulose conversion possibly due to the aggregation of cellulose microfibrills in bundles that hindered the enzymes penetration ${ }^{6,19}$. On the other hand, Zhu et al. ${ }^{20}$ removed xylans from hardwood species improving the enzymatic digestibility of the substrate due to dissolution of acetyl and uronic acid groups, while the lignin removal was not the most important factor for enhancing cellulose hydrolysis.

Autohydrolysis (also called hydrothermal pretreatment) uses water at relatively high temperatures $\left(140-200^{\circ} \mathrm{C}\right)$ under mild acidic conditions to partially fractionate LCB in a water-soluble fraction (with hemicelluloses and soluble lignin) and a water-insoluble fraction (mainly cellulose and insoluble lignin) ${ }^{21,22}$. The hemicelluloses are degraded to mono- and oligosaccharides leaving a pulp with the cellulose more susceptible to enzymatic hydrolysis ${ }^{23}$, ${ }^{24}$. Autohydrolysis pretreatment fails to remove high amounts of lignin, but the structure and distribution of this macromolecule over and inside the cell walls is altered, and has been demonstrated that, in some cases, it can affect the enzymatic access to the cellulose ${ }^{25}$. Some authors have reported that after hydrothermal and diluted acid pretreatments, the glucose yields from enzymatic hydrolysis was higher even when the lignin removal was minimal ${ }^{19,26}$.

Many researchers have indicated that the combination of processes such as autohydrolysis and alkaline washing could increase the accessibility of cellulose to the enzymatic hydrolysis by removing recalcitrant lignin, improving the cellulose digestibility ${ }^{24,27,28}$. Treatments with alkaline solutions on pretreated LCB cause the cleavage of ester bonds between lignin and hemicelluloses, increasing the porosity of the fibers ${ }^{29,30}$. However, it is unclear from where lignin is removed and what structural changes occur that can explain the higher accessibility and digestibility of cellulose. To contribute to the understanding of this important process, in this work, it was evaluated the pretreatment of Eucalyptus globulus wood chips by autohydrolysis followed by alkaline extraction in order to determine how the lignin structure and its distribution over the fibers affect the enzymatic saccharification of cellulose.

\section{EXPERIMENTAL}

\section{Raw material}

Eucalyptus globulus wood chips were obtained from a commercial plantation of a Chilean forest company located in the Biobío Region (Southern Chile). The wood chips $(2.5 \times 1.5 \times 0.2 \mathrm{~cm})$ from 12 year-old trees were thoroughly mixed to obtain a single uniform sample, air-dried until approximately $10 \%$ moisture, and stored in dry conditions before use.

\section{Autohydrolysis pretreatment}

The pretreatments were carried out in a rotary digester equipped with four independent 1.5-L vessels (REGMED, Brazil). The reactor was loaded with $100 \mathrm{~g}$ of wood chips, previously impregnated with distiller water for $12 \mathrm{~h}$, and treated with hot water $\left(1: 4 \mathrm{w} / \mathrm{v}\right.$ wood-water ratio) at $175^{\circ} \mathrm{C}$ for 15,30 , and 60 min, corresponding to severities ( $\mathrm{S}_{\mathrm{o}}$ ) of $3.69,3.81$ and 4.02 , respectively. $\mathrm{S}_{\mathrm{o}}$ was calculated according to Sixta et al. ${ }^{31}$. After cooking, the pretreated material (pulp) was disintegrated in a TAPPI laboratory blender, thoroughly washed 
with tap water, and centrifuged. The total pulp yield was determined based on the weight of the pulp divided by the weight of the wood chips (both on a dry basis) multiplied by 100 . The pretreated samples were stored in plastic bags at $4^{\circ} \mathrm{C}$ until further use.

\section{Alkaline extraction}

Pulps obtained from the autohydrolysis pretreatment were subjected to an alkaline extraction with $\mathrm{NaOH}($ aq. $) 8 \%(\mathrm{p} / \mathrm{v})$ at $1: 10(\mathrm{w} / \mathrm{w})$ pulp/solution ratio (on dry pulp basis), at $40^{\circ} \mathrm{C}$ for $14 \mathrm{~h}$, to remove leachable lignin. The alkaline extraction material was washed with water until $\mathrm{pH}$ 5.5. The pulps were centrifuged to $35 \%$ consistency and stored at $4^{\circ} \mathrm{C}$ until use.

\section{Chemical characterization of wood and pretreated samples}

Milled wood samples (40/60 mesh) were extracted with ethanol/toluene according to the TAPPI method $204 \mathrm{~cm}-97$. Chemical characterization of extracted wood and pulps was determined according to the methodology described by Ferraz et $\mathrm{al}^{32}$. A sample of $300 \mathrm{mg}$ was weighed in test tube and $3 \mathrm{~mL}$ of $72 \%(\mathrm{w} / \mathrm{w}) \mathrm{H}_{2} \mathrm{SO}_{4}$ was added. The hydrolysis was carried out in a water bath at $30^{\circ} \mathrm{C}$ for $1 \mathrm{~h}$ with stirring every $10 \mathrm{~min}$. Subsequently, the acid was diluted to $4 \%$ (w/w) with $84 \mathrm{~mL}$ of distilled water, and the mixture was transferred to a $250-\mathrm{mL}$ Erlenmeyer flask and autoclaved for $1 \mathrm{~h}$ at $121^{\circ} \mathrm{C}$. The residual material was cooled, filtered through a number 4 sintered glass filter and washed with water. The solid fraction (insoluble lignin) was dried at $105^{\circ} \mathrm{C}$ and weighed. The acid-soluble lignin was determined by measuring the absorbance at $205 \mathrm{~nm}$ using $110 \mathrm{~L} \mathrm{~g} \mathrm{~g}^{-1} \mathrm{~cm}^{-1}$ as the absorptivity. Total lignin was the sum of the soluble and insoluble lignin. The concentration of monomeric sugars in the soluble fraction was determined by high-performance liquid chromatography (HPLC) with a refractive index detector and Aminex HTX-87H column (BioRad, USA) at $45{ }^{\circ} \mathrm{C}$ with a mobile phase of $0.005 \mathrm{~mol} \mathrm{~L}^{-1} \mathrm{H}_{2} \mathrm{SO}_{4}$ and a flow rate of $0.6 \mathrm{~mL} \mathrm{~min}^{-1}$. Glucose, xylose, arabinose and acetic acid were used as external calibration standards. Hydrolysis factors used for the conversion of glucose to glucans, xylose to xylans, arabinose to arabinosyl groups and acetic acid to acetyl groups were $0.9,0.88,0.88$ and 0.72 , respectively. All samples were analyzed in triplicate.

\section{Enzymatic hydrolysis}

The pretreated pulps (with and without $\mathrm{NaOH}$ extraction) were enzymatically hydrolyzed in $250-\mathrm{mL}$ Erlenmeyer flasks at $10 \%(\mathrm{w} / \mathrm{v})$ consistency in sodium citrate buffer solution $\left(\mathrm{pH} \mathrm{4.8,0.05} \mathrm{mol} \mathrm{L}^{-1}\right)$ using commercial cellulases enzymes (NS-22128 CCN03128; 71 FPU $\mathrm{mL}^{-1}$ ) supplemented with $\beta$-glucosidase (NS-22128 DCN00216;265 CB mL $\mathrm{m}^{-1}$ ) at $50^{\circ} \mathrm{C}$ in a shaker at $150 \mathrm{rpm}$ for $72 \mathrm{~h}$. The enzyme dosages per gram of dry material were $20 \mathrm{FPU}$ and $20 \mathrm{CBU}$ of cellulase and $\beta$-glucosidase, respectively. The content of glucose released was analyzed by HPLC. The yield was expressed as the percentage of glucose released in the enzymatic hydrolysis divided by the total amount of glucose available in the pretreated material. All measurements were performed in triplicate.

\section{Analytical pyrolysis (Py-GC/MS)}

Samples (approximately $150 \mu \mathrm{g}$ ) of E. globulus wood and pulps obtained by different autohydrolysis conditions were subjected to analytical pyrolysis using a 2020 micro-furnace pyrolyzer (Frontier Laboratories Ltd.) connected to an Agilent 6890 gas chromatograph with an Agilent 5973 (Agilent Technologies Inc., USA) mass selective detector operated in electron impact ionization mode (EI at $70 \mathrm{eV}$ ). The system was equipped with a DB-1701 fused-silica capillary column $(30 \mathrm{~m} \times 0.25 \mathrm{~mm}$ i.d., $0.25 \mu \mathrm{m}$ film thickness). The pyrolysis was performed at $500^{\circ} \mathrm{C}$ and the $\mathrm{GC}$ oven temperature was programmed from $50^{\circ} \mathrm{C}$ (1 min) to $100^{\circ} \mathrm{C}$ at $30^{\circ} \mathrm{C} \mathrm{min}-1$ and then to $290^{\circ} \mathrm{C}(10 \mathrm{~min})$ at $6^{\circ} \mathrm{C} \mathrm{min}{ }^{-1}$. Helium was the carrier gas $\left(1 \mathrm{~mL} \mathrm{~min}^{-1}\right)$. The compounds were identified by comparing their mass spectra with those from Wiley and NIST libraries, as well as, with those reported in the literature ${ }^{33,34}$. Peak molar areas were calculated for the lignin-degradation products, the summed areas were normalized, and the data for two repetitive analyses were averaged and expressed as percentages. No attempt was made to calculate the response factor for every single compound released in the pyrolysis.

\section{D-NMR spectroscopy}

Dry pretreated materials were ball-milled using a Retsch PM100 vibratory ball mill vibrating at $600 \mathrm{rpm}$ in zirconium dioxide $\left(\mathrm{ZrO}_{2}\right)$ vessels $(50 \mathrm{~mL})$ containing $\mathrm{ZrO}_{2}$ ball bearings $(10 \times 10 \mathrm{~mm})$. Each $200 \mathrm{mg}$ of sample was ground for $1 \mathrm{~h}$ (in $10 \mathrm{~min}$ on $/ 5 \mathrm{~min}$ off interval cycles). The ball-milled pretreated material (approximately $50 \mathrm{mg}$ ) was transferred into $5 \mathrm{~mm}$ NMR tubes. The sample was distributed as well as possible off the bottom and up the sides of the tube. DMSO- $d_{6}$ :Pyridine- $d_{5}(4: 1, \mathrm{v} / \mathrm{v})$ was carefully added down the side of the NMR tube. The NMR tube was sonicated for 30 min until the turbid gel began to clear and was apparently homogeneous according to the method developed by Kim et al. ${ }^{35}$. The 2D heteronuclear single quantum coherence (HSQC) spectra were recorded at $25^{\circ} \mathrm{C}$ on a Bruker AVANCE $700 \mathrm{MHz}$ spectrometer fitted with a cryogenically cooled $5 \mathrm{~mm}$ gradient probe with inverse geometry using Bruker's standard pulse sequence.

\section{Scanning electron microscopy (SEM)}

Fiber surface analyses of pretreated samples before and after alkaline extraction were performed by SEM using a Jeol JSM-6380LV instrument under a high vacuum operating with a secondary electron detector. The samples were dried at room temperature and coated with conductive gold paint with a 500 A particle size in a S150 Edwars Sputter Coater. Imaging was performed at a beam accelerating voltage of $20 \mathrm{kV}$ with tungsten filament as the electron source.

Laser scanning confocal fluorescence microscopy (LSCM)

A LSM710 confocal microscope (Axio Imager.Z1, Carl Zeiss) with a ZEN 2008 that uses an excitation laser at $\mathrm{Ar} 488 \mathrm{~nm}$ over an emission range of $490 \mathrm{~nm}-560 \mathrm{~nm}$ and a 20x EC Plan Neofluar objective (N.A. 0.5) zoom 1.7. Software v. 5.0 (Zeiss) was used to acquire multi-channel fluorescence images of the pulps that were suspended in water prior the analysis.

\section{RESULTS AND DISCUSSION}

\section{Chemical composition}

Yield of solids and chemical characteristics of wood and autohydrolysis' pulps of E. globulus samples are summarized in Table 1. Autohydrolysis is an effective pretreatment method to reduce LCB recalcitrance by removing hemicelluloses, disrupting lignin-hemicellulose matrix and redistributing lignin in the cell wall layers. Alkaline extraction or washing can remove leachable lignin accumulated on the surface of the fiber after the hydrothermal treatment. The yield of solids after autohydrolysis (87.5-74.9\%) decreased by approximately $20 \%$ after alkaline extraction (66.1-55.6\%) (Table 1$)$. The content of xylans decreased from 14.4 in the raw material to $9.0 \%, 6.1 \%$ and $3.7 \%$ in the pulps obtained at $\mathrm{S}_{0}=3.69,3.81$ and 4.02 , respectively, being the xylans retention [xylans amount in the solid/xylans amount in the raw material] between $76,1-28.8 \%$ and, after the alkaline extraction, the xylans retention was $34.6-25.7 \%$. The content of acetyl groups was $3.4 \%$ in the raw material, while in the pulps were $1.8,1.1$ and $0.7 \%$ in the pulp obtained at $\mathrm{S}_{0}=3.69 ; 3.81$ and 4.02 , respectively, and were not detected in the alkaline extracted pulps. The content of glucans in pulp basis varied between 53.1 and $62.5 \%$, depending on the severity, and increased after alkaline extraction, with yields between $70.5 \%$ and $83.4 \%$. In wood basis [(yield of solids $/ 100) *$ glucans amount], no glucans losses were observed with retention higher than $99 \%$ in the pretreated pulps (with and without alkaline extraction). Lignin content in the pulps after autohydrolysis, independent of the severity, was similar to that present in the untreated wood $(\sim 24 \%)$, representing a lignin retention [(lignin amount in solids/lignin amount in the raw material)*100] between 84.4 and $71.1 \%$. After alkaline extraction, the lignin content in the pulp was reduced to $18.5 \%, 14.5 \%$ and $7.9 \%$ for severities $\mathrm{S}_{0}=3.69, \mathrm{~S}_{0}=3.81, \mathrm{~S}_{0}=4.02$, respectively, being the lignin retention between 26.1 and $17.8 \%$.

\section{Enzymatic Hydrolysis}

Pulps obtained from autohydrolysis pretreatment at different severities, with and without alkaline washing, were used as substrate for enzymatic hydrolysis to assess the cellulose digestibility (Figure 1). After $72 \mathrm{~h}$, samples achieved glucans to glucose conversion conversions [(glucose released by enzymatic hydrolysis/glucose in the raw material)*100] of 37.9, 57.9 and $64.6 \%$, for severity factors of $3.69,3.81$ and 4.02 , respectively. The conversions for the pulps submitted to the alkaline extraction were approximately the same as the unextracted samples. Only at the lower severities there is an increase in the hydrolysis rate at intermediate time (Fig. 1), but the final value achieved for cellulose saccharification was similar.

Some authors suggested that a partial delignification enhanced the cellulose digestion by enabling enzyme access to the cellulose $e^{6,36,37}$. In the present work, the removal of leachable lignin does not affect the yield of saccharification, suggesting that the lignin content per se it is not the only factor affecting cellulose hydrolysis. Other parameters should be taken into account, such as lignin structure and distribution in the pretreated fibers. 
Table 1. Chemical composition of wood chips and pretreated material obtained after autohydrolysis of Eucalyptus globulus.

\begin{tabular}{|c|c|c|c|c|c|c|}
\hline Samples & $\begin{array}{c}\text { Yield of solids } \\
(\%)\end{array}$ & $\begin{array}{c}\text { Glucans } \\
(\%)\end{array}$ & $\begin{array}{c}\text { Xylans } \\
(\%)\end{array}$ & $\begin{array}{c}\text { Arabinosyl groups } \\
(\%)\end{array}$ & $\begin{array}{c}\text { Acetyl groups } \\
(\%)\end{array}$ & $\begin{array}{c}\text { Lignin } \\
(\%)\end{array}$ \\
\hline Untreated wood & 100 & $46.9 \pm 0.2$ & $14.4 \pm 0.2$ & $0.7 \pm 0.1$ & $3.4 \pm 0.3$ & $24.9 \pm 0.4$ \\
\hline So=3.69 & 87.5 & $53.1 \pm 0.8$ & $9.0 \pm 0.1$ & nd & $1.8 \pm 0.1$ & $24.0 \pm 0.2$ \\
\hline So=3.81 & 83.6 & $58.3 \pm 0.8$ & $6.1 \pm 0.1$ & nd & $1.1 \pm 0.1$ & $24.4 \pm 0.3$ \\
\hline So=4.02 & 74.9 & $62.5 \pm 0.7$ & $3.7 \pm 0.1$ & nd & $0.7 \pm 0.1$ & $23.6 \pm 0.6$ \\
\hline So=3.69+AE & 66.1 & $70.5 \pm 0.1$ & $6.4 \pm 0.1$ & nd & nd & $18.5 \pm 0.4$ \\
\hline So=3.81+AE & 64.2 & $75.0 \pm 0.5$ & $6.5 \pm 0.1$ & nd & nd & $14.5 \pm 0.2$ \\
\hline So=4.02+AE & 57.6 & $83.4 \pm 1.1$ & $3.8 \pm 0.1$ & nd & nd & $7.9 \pm 0.3$ \\
\hline
\end{tabular}

So: severity factor, AE: alkaline extraction, nd: not detected.

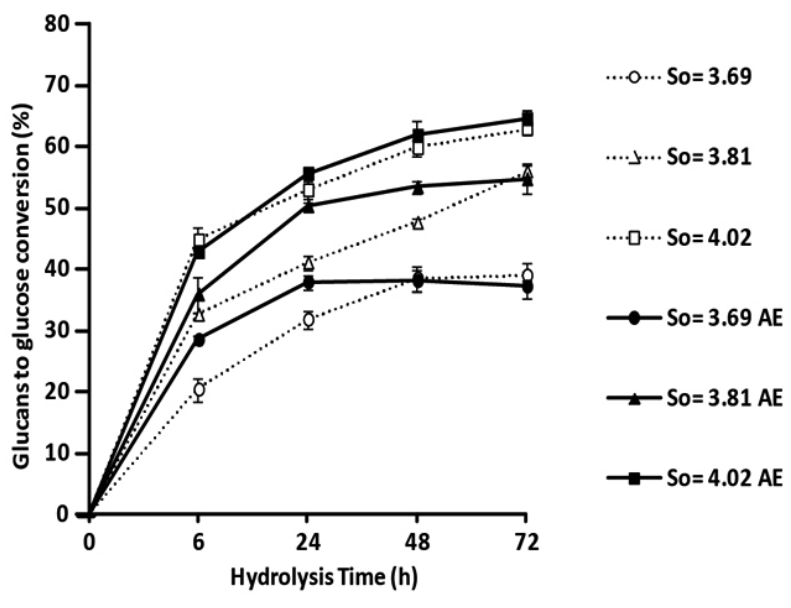

Figure 1. Enzymatic hydrolysis of E. globulus pulps obtained by autohydrolysis at different severity with and without alkaline extraction.

\section{Lignin distribution}

Figure 2 and Figure 3 showed the SEM and LSCM images, respectively, of the autohydrolysis pretreated samples obtained at different severities, with or without alkaline extraction. In the SEM images, it is observed that the surface of the pretreated material was not disrupted in the samples obtained at $\mathrm{S}=$ 3.69 (Fig. 2a), and as the severity increases $\left(\mathrm{S}_{\mathrm{o}}=3.81\right.$ and $\left.\mathrm{S}_{\mathrm{o}}=4.02\right)$, the fibers started to be peeled off the surface (Figs. $2 b$ and 2c). Particularly, in Fig. 2c, with the disaggregation of the fibers, small droplets of lignin are observed over the fibers. With the alkaline washing, these droplets are removed from the fibers. The formation of discrete lignin droplets on the cell wall surface is in concordance with the reported by others authors that also used hydrothermal pretreatments for $\mathrm{LCB}^{38,39}$. In the LSCM images (Fig. 3), due to the lignin intrinsic autofluorescence $(530 \mathrm{~nm})$, it is possible to localize the lignin on the cell wall. In this case, it is also observed small droplets inside the fibers (Fig. $3 c)$ that were removed and not observed in the alkaline extracted sample.
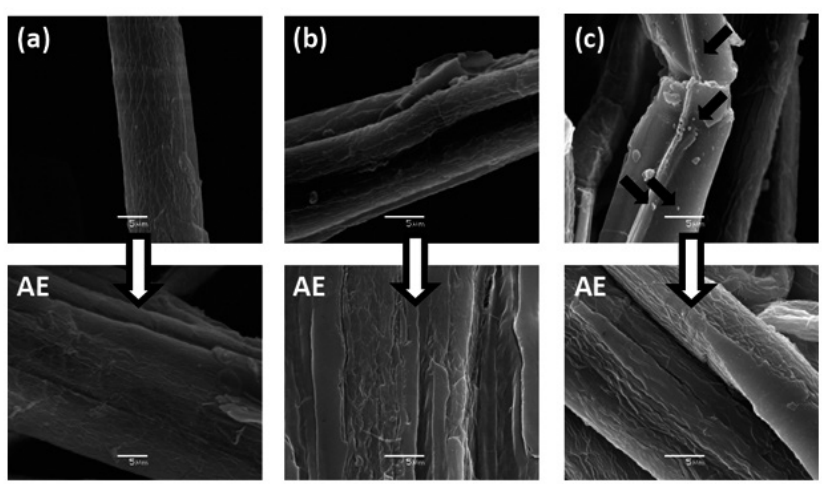

Figure 2. SEM images of fibers from autohydrolysis pulps of $E$. globulus after different pretreatment conditions: (a) $\mathrm{S}_{0}=3.69$, (b) $\mathrm{S}_{0}=3.81$ and (c) $\mathrm{S}$ $=4.02$ (droplets over the fiber are shown with black arrows). AE denotes each pulp after alkaline extraction in treatment. $\mathrm{S}_{\mathrm{o}}=4.02$ after $\mathrm{AE}$ treatment not shown droplets over the fiber.
The main effect of the autohydrolysis pretreatment is the removal of hemicelluloses and a partial fragmentation of the lignin with a slight delignification. As the pretreatment severity increases, the cleavage of bonds in the lignin-carbohydrate complex is increased, and free hydrophobic lignin molecules in a hydrophilic medium are forced to recondense, forming small spheres or droplets that are redeposited not only on the external surface of the fiber, but also inside the fibers. The relocalization of lignin in the hydrothermal pretreatment is likely to be as important as lignin removal to improve digestibility of cellulose by opening up the structure of the cell wall matrix, as also reported Donohoe et al..$^{38}$.
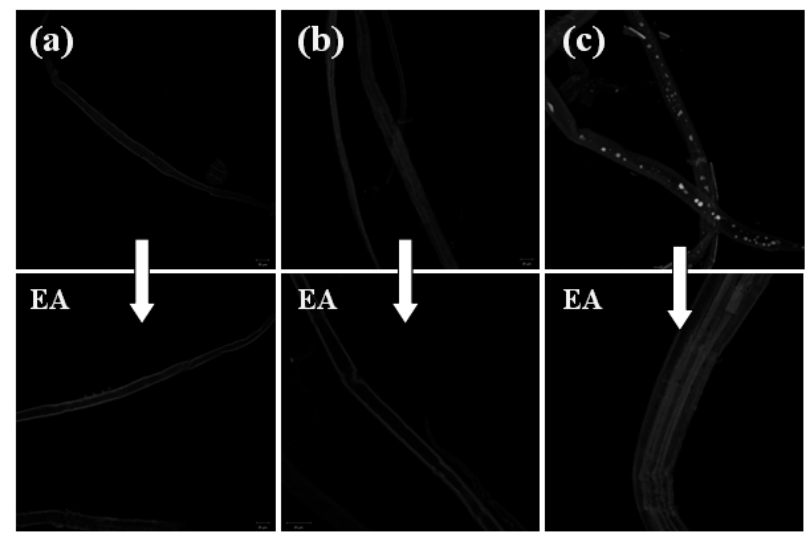

Figure 3. LSCM images of fibers from autohydrolysis pulps of E. globulus after different pretreatment conditions: (a) $\mathrm{S}_{0}=3.69$, (b) $\mathrm{S}_{0}=3.81$ and (c) $\mathrm{S}_{0}$ $=4.02$. AE denotes each pulp after alkaline extraction treatment. (3c) shown droplets inside the fiber who disappear after AE treatment.

\section{Py-GC/MS}

Structural characteristics of lignin have also been considered an important factor to explain the variations in LCB saccharification after a pretreatment step. Depending on its relative abundance and distribution, as well as, the abundance of linkages and the syringyl/guayacil (S/G) ratio, lignin presents different reactivity that affects the digestibility of biomass. The abundance of $\mathrm{S}$ and $\mathrm{G}$ monomers in lignin structure of autohydrolysis samples of $E$. globulus was evaluated by means of analytical pyrolysis (Py-GC/MS), which is a thermochemical technique that can provide structural and compositional information of biomass ${ }^{34}$. Figure 4 shows the pyrograms obtained for the different samples analyzed and Table 2 lists the peak assignments for the most representative compounds obtained from the lignin degradation during sample pyrolysis that were associated with S-type and G-type monomers. The lignin side chains were not oxidized by autohydrolysis or by subsequent alkaline extraction. The S-type aldehyde units and G-type ketone units, present in the starting material, were removed by alkaline extraction; S-type units having ketone groups in the lateral chain were not removed. By autohydrolysis, both $\mathrm{S}$ and $\mathrm{G}$ long side chains were degraded, the intensity of its signals decreased as the severity was increased. While, the intensity of the signals of the units with small side chains, such as syringol, increased as the severity was increased. By alkaline extraction units with small side chains, like syringol, methyl syringol and guaiacol, were not removed. Formation of new structures was not observed in any of the pretreated samples. S/G ratio ranged between 6.7 and 6.3 for the samples obtained by autohydrolysis and between 6.0 and 6.1 for the alkaline extracted samples. Despite the small difference, it was not significant 
in comparison with $\mathrm{S} / \mathrm{G}$ ratio of untreated samples (6.5) indicating that no preferential hydrolysis and/or condensation of S or G units occurred under the employed conditions.

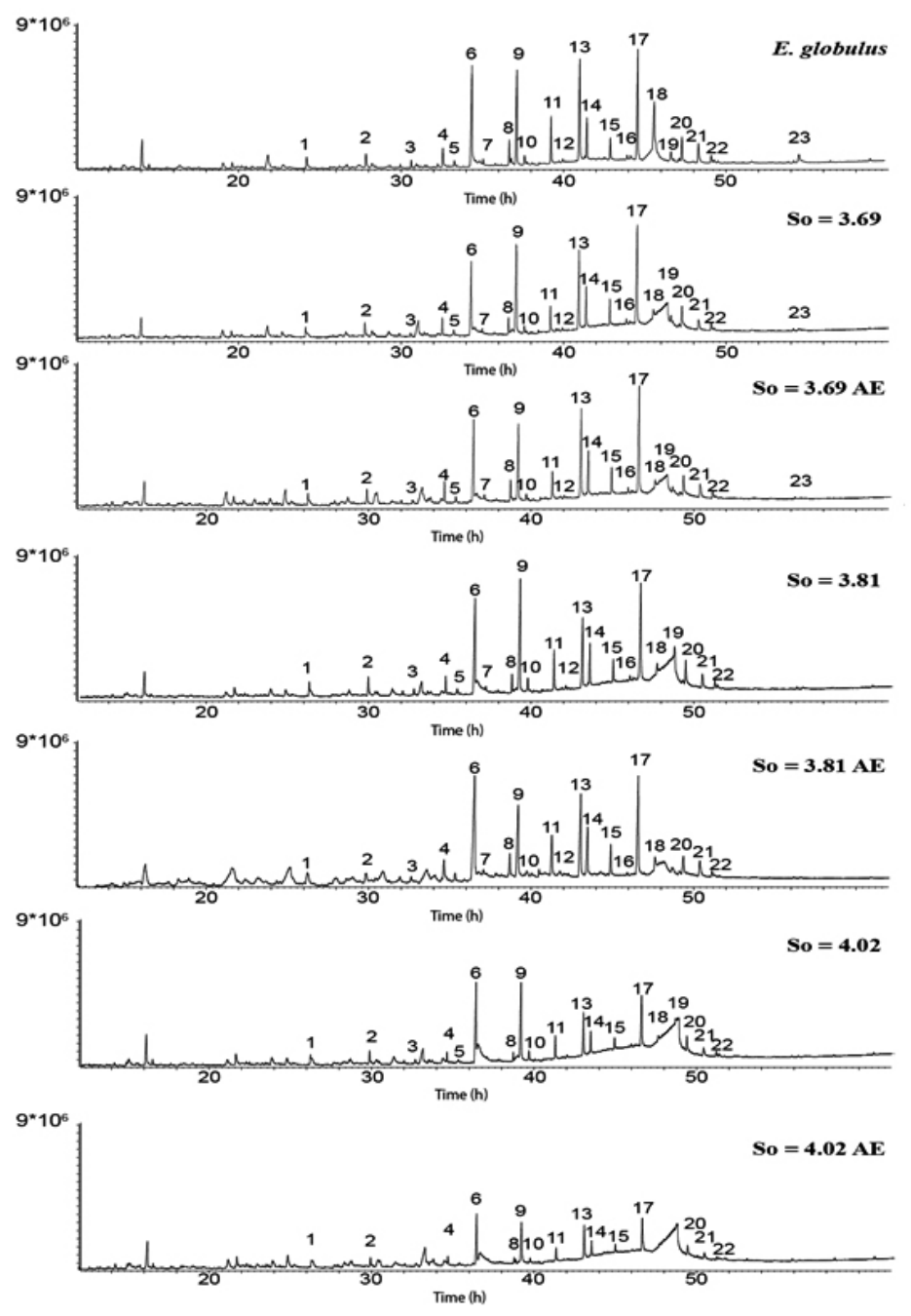

Figure 4. Representative pyrograms of E. globulus wood and autohydrolysis pretreated samples. $\mathrm{S}_{\mathrm{o}}$ : severity factor, AE: alkaline extraction. Peak assignment for lignin-derivatives identified compounds are shown in Table 2.
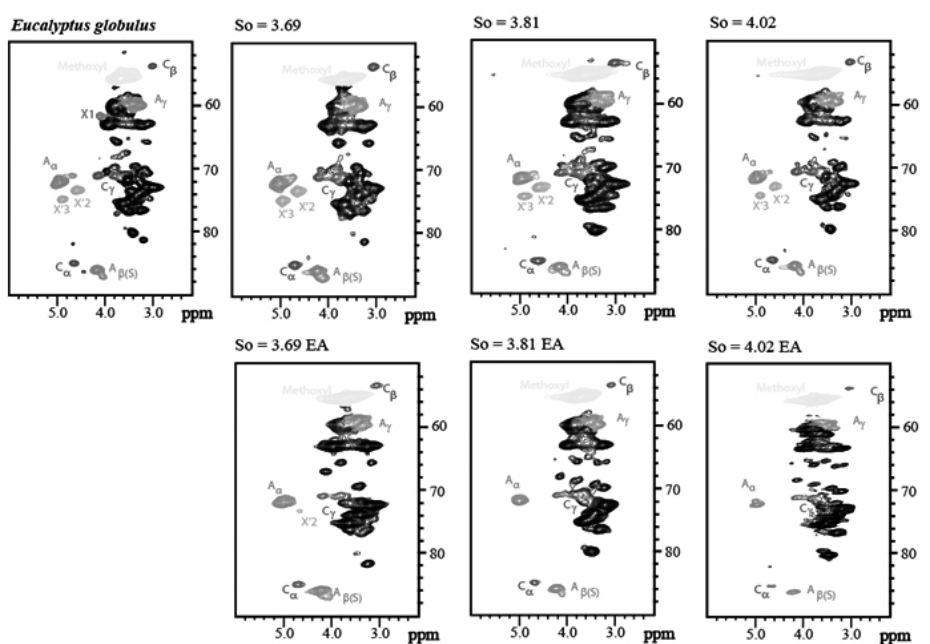

So $=3.81 \mathrm{EA}$
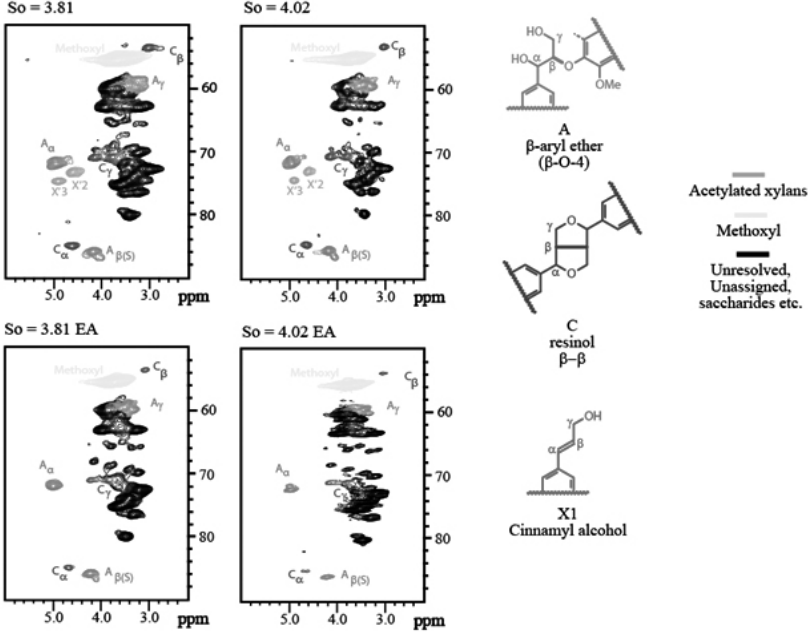

Unassigned,

Figure 5. Expanded side chain region of HSQC spectra of untreated and autohydrolysis pulps of E. globulus. 
Table 2. Main compounds from guaiacyl and syringyl (S) units of lignin obtained after analytical pyrolysis of E. globulus samples.

\begin{tabular}{|c|c|c|c|c|c|c|c|c|}
\hline Peak & Compound & E. globulus & $\mathrm{So}=3.69$ & $\begin{array}{c}\mathrm{So}=3.69+ \\
\mathrm{AE}\end{array}$ & $\mathrm{So}=3.81$ & $\begin{array}{c}S_{0}=3.81+ \\
\mathbf{A E}\end{array}$ & $\mathrm{So}=4.02$ & $\begin{array}{c}\text { So }=4.02+ \\
\mathbf{A E}\end{array}$ \\
\hline 1 & guaiacol & 2.1 & 1.3 & 1.5 & 1.8 & 1.8 & 1.5 & 1.2 \\
\hline 2 & 4-methylguaiacol & 2.5 & 3.1 & 3.0 & 3.4 & 1.6 & 3.9 & 4.0 \\
\hline 3 & 4-ethylguaiacol & 0.8 & 0.5 & 0.4 & 0.8 & 1.8 & 1.1 & 0.7 \\
\hline 4 & 4-vinylguaiacol & 2.6 & 2.9 & 3.5 & 2.2 & 3.3 & 2.3 & 3.0 \\
\hline 5 & eugenol & 0.5 & 0.5 & 0.5 & 0.3 & 0.9 & 0.3 & 0.4 \\
\hline 6 & syringol & 17.8 & 14.3 & 15.8 & 16.2 & 25.3 & 20.0 & 21.1 \\
\hline 7 & $c$-isoeugenol & 0.5 & 0.5 & 0.5 & 0.5 & 0.5 & 0.3 & 0.3 \\
\hline 8 & $t$-isoeugenol & 2.5 & 2.3 & 2.3 & 2.1 & 4.0 & 1.7 & 1.6 \\
\hline 9 & 4-methylsyringol & 13.8 & 18.8 & 14.0 & 22.5 & 9.0 & 22.2 & 18.7 \\
\hline 10 & vanillin & 1.2 & 1.5 & 1.1 & 2.0 & 0.1 & 2.3 & 2.0 \\
\hline 11 & 4-ethylsyringol & 5.2 & 3.6 & 4.0 & 5.1 & 4.5 & 5.0 & 4.8 \\
\hline 12 & acetovanillone & 0.5 & 0.5 & 0.4 & 0.6 & 0.4 & 0.7 & 0.7 \\
\hline 13 & 4-vinylsyringol & 13.7 & 13.7 & 14.9 & 10.1 & 14.5 & 9.9 & 13.8 \\
\hline 14 & 4-allylsyringol & 4.1 & 5.4 & 6.0 & 4.8 & 5.1 & 4.3 & 4.4 \\
\hline 15 & $c$-4-propenylsyringol & 2.2 & 3.2 & 3.3 & 2.5 & 2.7 & 1.9 & 1.9 \\
\hline 16 & 4-propenylsyringol & 0.5 & 0.9 & 0.7 & 0.6 & 0.4 & 0.8 & - \\
\hline 17 & $t$-propenylsyringol & 13.1 & 18.1 & 19.0 & 15.7 & 13.5 & 13.1 & 12.8 \\
\hline 18 & syringaldehyde & 7.0 & 2.1 & 1.8 & 1.3 & 0.4 & 1.3 & 0.9 \\
\hline 19 & homosyringaldehyde & 1.3 & 0.5 & 0.5 & 0.4 & - & 0.2 & 0.2 \\
\hline 20 & acetosyringone & 2.9 & 3.1 & 3.0 & 3.4 & 3.4 & 3.6 & 3.4 \\
\hline 21 & syringylacetone & 2.7 & 1.8 & 2.6 & 2.4 & 5.6 & 2.3 & 2.6 \\
\hline 22 & propiosyringone & 0.7 & 1.1 & 1.0 & 1.2 & 0.7 & 1.0 & 1.0 \\
\hline \multirow[t]{2}{*}{23} & $t$-sinapaldehyde & 1.5 & 0.4 & 0.2 & 0.3 & 0.7 & - & 0.3 \\
\hline & $S / G=$ & 6.5 & 6.7 & 6.6 & 6.3 & 6.0 & 6.1 & 6.1 \\
\hline
\end{tabular}

\section{D NMR-HSQC}

Solution-state two-dimensional (2D) nuclear magnetic resonance (NMR) gives an interpretable structural fingerprint of the lignin and carbohydrate components of the cell wall without structural modification beyond that applied during the ball milling and ultrasonication steps. This approach constitutes a rapid method to compare the structural characteristics of lignin and oligosaccharides ${ }^{35,40}$. The HSQC NMR (1-bond ${ }^{13} \mathrm{C}^{-1} \mathrm{H}$ correlation) spectra of lignin from E. globulus pulps obtained via autohydrolysis pretreatment and alkaline extraction are shown in Figures 5 and 6. The signals were assigned using a published database $\mathrm{e}^{41}$.

The $\beta$-aryl ether $\mathrm{A}_{\alpha}$ contour (light blue, Fig. 5) is observed in all the hydrothermal pretreated samples, but he contour is smaller in the sample obtained at the higher severity $(\mathrm{S}=4.02)$, giving qualitative evidence of the cleavage of $\beta$-aryl ether bonds. These signals decreased after alkaline extraction, which could indicate the presence of such units in the leachable lignin removed by the alkaline process. Many studies have indicated that the cleavage of $\beta-\mathrm{O}-4$ ' units is the most important reaction during the acidic pretreatment of hardwoods, forming new phenolic lignin units and Hibbert's ketone type substructures ${ }^{6,7,42}$. The formation of phenolic units is an important change in the lignin structure to improve the enzyme accessibility to cellulose substrate for further enzymatic hydrolysis ${ }^{43}$. Furthermore, $\beta$-aryl ether cleavage can result in new and more stable bonding, such as the C-C in the lignin structure $^{9,44}$. Substructures types resinol (purple, Fig. 5) are fairly stable ${ }^{6,9}$, ${ }^{41,45}$ and withstand the hydrothermal pretreatment, even at elevated severities, but the intensity of these signals decreased by the alkaline extraction, possibly because the lignin with such units were redeposited on the surface of the fiber and were removed in the alkaline washing. Also, the oxidized lignin at $\alpha$ position was eliminated in the alkaline extraction. Terminal groups units, such as cinnamyl alcohol, (pink, Fig. 5) were degraded by autohydrolysis, being not observed in the samples obtained at the higher severity. Such subunits were not removed by the alkaline extraction. The amount of acetylated xylans (orange, Fig. 5) was reduced during autohydrolysis pretreatment, and the intensity of these signals decreased by increasing the severity, and also by the alkaline extraction (it was observed a preference for removing the acetyl groups in the $\mathrm{C}_{3}$ of the xylans, and deacetylation of the anomeric carbon). This change is expected for the progressive removal and deacetylation of hemicelluloses, which was confirmed based on the decrease and disappearance of the acetyl cross peaks as the severity increased at $\delta_{\mathrm{C}} / \delta_{\mathrm{H}} 20.9 / 2.01$ (not shown). The LCB deacetylation contributes to the enzymatic digestibility of cellulose in the pretreated material, which is consistent with that reported by Zhang et al. ${ }^{46}$, who observed that the removal of acetyl group in wheat straw and giant reed improved the accessibility of cellulases to cellulose.

The aromatic rings of lignin units are the main cross-signals. Syringyl units (S, dark green, Fig. 6) with correlation signals $\left(\mathrm{C}_{26}-\mathrm{H}_{2,6}\right)$ were observed at $\delta_{\mathrm{C}} / \delta_{\mathrm{H}} 104.2 / 6.8$ for all samples, independent of the severity at which samples were obtained and the respective alkaline extraction. The guaiacyl units $(\mathrm{G}$, red, Fig. 6) correlated with the 2-positon $\left(\mathrm{C}_{2}-\mathrm{H}_{2}\right)$ at $\delta_{\mathrm{C}} / \delta_{\mathrm{H}} 111 / 7.0$, with the five position $\left(\mathrm{C}_{5}-\mathrm{H}_{5}\right)$ at $\delta_{\mathrm{C}} / \delta_{\mathrm{H}} 115 / 6.7-7.0$, and with the $\mathrm{C}_{6}-\mathrm{H}_{6}\left(\delta_{\mathrm{C}} / \delta_{\mathrm{H}} 119 / 6.8\right)^{41}, \mathrm{C} 2$ and $\mathrm{C} 6$ position $\mathrm{G}$ units decreased with alkaline extraction. These results agree with those obtained with the analytical pyrolysis where no major change was observed with respect to the chemical composition of lignin after autohydrolysis pretreatment and subsequent alkaline washing. 


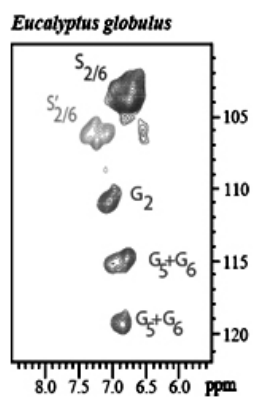

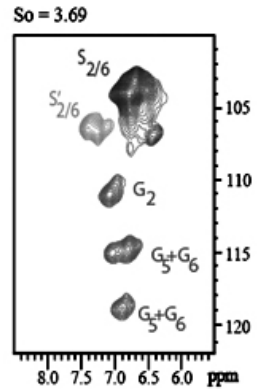

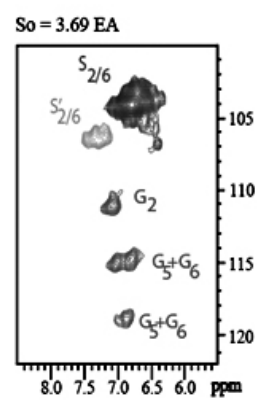

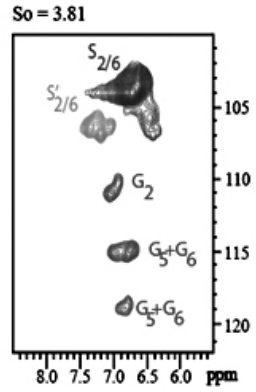

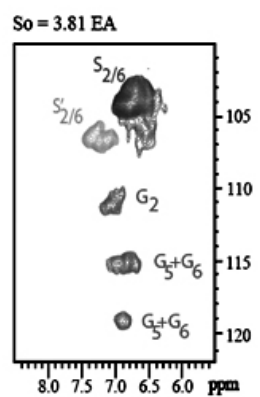

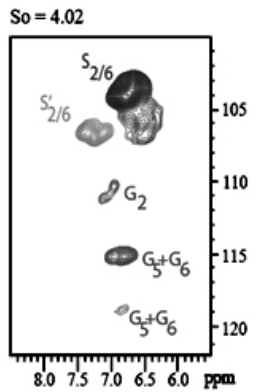

$\mathrm{So}=4.02 \mathrm{EA}$

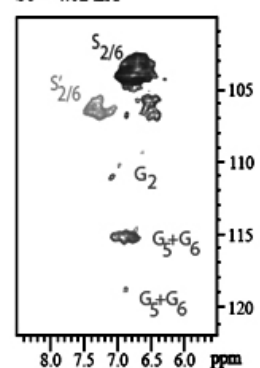

8075706.5600 ppon
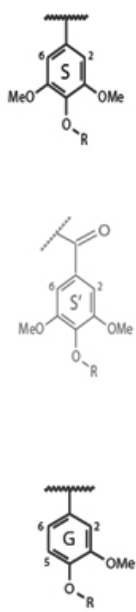

Figure 6. Expanded unsaturated region of HSQC spectra of untreated and autohydrolysis pulps of E. globulus.

\section{CONCLUSIONS}

Based on the results obtained, the accessibility to the cellulose by the enzymes during the saccharification of pulps obtained by the autohydrolysis process using different pretreatment severities and with or without alkaline washing could be attributed to the decrease in the content of xylans and, the changes in structure and redistribution of the lignin over the fibers. These resulted in a decrease in the recalcitrance of lignin and an increase in the porosity and contact area of the enzymes with cellulose. Under the conditions studied, the lignin is more recalcitrant when remained homogeneously distributed in the cell wall than when heterogeneously redistributed as droplets, which allows a better access to the cellulose by the enzymes. The process is slightly faster when applying a removal of the leachable lignin by alkaline treatment; however the effect in the final results (glucans to glucose conversion) was not significant.

\section{ACKNOWLEDGMENTS}

The financial support from Fondecyt (grant 1110828), Conicyt (PhD fellowship 63100148), Conicit Costa Rica (PhD fellowship FI-59-2010), Instituto de Recursos Naturales y Agrobiología de Sevilla (IRNAS), Seville and DOE Great Lakes Bioenergy Research Center (DOE Office of Science BER DE-FC02-07ER64494) is acknowledged.

\section{REFERENCES}

1.- S. Ahola, X. Turon, M.Osterberg, J. Laine, O.J. Rojas, Langmuir 24, 11592-11599, (2008)

2.- P. Alvira, E. Tomás-Pejó, M. Ballesteros, M.J. Negro, Bioresource Technology 101, 4851-4861, (2010).

3.- A. B. Moldes, J. M Cruz, J. M. Domíniquez, Agr Food Sci Finland 11, 51$58,(2008)$.

4.- Y. Sun and J. Cheng, Bioresource Technology 83, 1-11, (2002).

5.- L. Zhu, J. O’Dwyer, V. Chang, C. Granda, M. Holtzapple, Bioresource Technology 99, 3817-3828, (2008).

6.- Y. Pu, F. Hu, F. Huang, B.H. Davison, A. J. Ragauskas, Biotechnol Biofuels 6, 15, (2013).

7.- R. Santos, P. Hart, H. Jameel, H. Chang, Bioresource Technology 8, 14561477, (2013).

8.- V. Arantes and J. Saddler, Biotechnol Biofuels 3, 1-11, (2010).

9.- S. Cao, Y. Pu, M. Studer, C. Wyman, A. Ragauskas, Rsc Adv 2, 1092510936, (2012).
10..- $\quad$ A. Jun, U. W, Tschirner, Z. Tauer, Biomass Bioenerg 37, 229-236, (2012).

11.- H. Palonen, VTT Technical Research Centre of Finland. 1-80, (2004).

12.- J. Weng, X. Li, N. Bonawitz, C. Chapple, Curr Opin Biotech 19, 166-172, (2008).

13.- R. Kumar and C. E. Wyman, Biotechnol progr 25, 807-819, (2009).

14.- F. Hu, S. Jung, A. Ragauskas, ACS Sustainable Chem Eng 1, 62-65, (2013).

15.- H. Li, Y. Pu, R. Kumar, A. J. Ragauskas, C. E. Wyman, Biotechnol Bioeng 111, 485-492, (2014).

16.- B. Yang and C. E. Wyman, Biotechnol Bioeng 94, 611-617, (2006).

17.- X. Pan, D. Xie, N. Gilkes, D. J. Gregg, J. N. Saddler, Twenty-Sixth Symposium on Biotechnology for Fuels and Chemicals, Springer.121-124, 1069-1079, (2005).

18.- S. Nakagame, R. P. Chandra, J. N. Saddler, Biotechnol Bioeng 105, 871$879,(2010)$

19.- C. Ishizawa, T. Jeoh, W. Adney, M. Himmel, D. Johnson, M. Davis, Cellulose 16, 677-686, (2009)

20.- W. Zhu, C. J. Houtman, J. Y. Zhu, R. Gleisner, K. F. Chen, Process Biochem 47, 785-79, (2012).

21.- J. Castro, C. Parra, M. Yáñez, R. Rojas, R. J. Teixeira, Baeza, J. Freer, Ind Eng Chem Res 52, 5713-5720, (2013).

22.- P. Reyes, R. Teixeira, J. Rodriguez, P. Fardim, B. Vega, J Chi Chem Soc 58, 1614-1618, (2013).

23.- F. Carvalheiro, L. C. Duarte, F. M. Gírio, J Sci Ind Res India 67, 849-864, (2008).

24.- A. Romaní, G. Garrote, J. L.Alonso, J. C. Parajó, Bioresource Technol 101, 8706-8712, (2010).

25.- M. Selig, S. Viamajala, S. Decker, M. Tucker, M. Himmel, T. Vinzant, Biotechnol Progr 23, 1333-1339, (2007).

26.- J. D. DeMartini, S. Pattathil, U. Avci, K. Szekalski, K. Mazumder, M. G. Hahn, C. E. Wyman, Energ Environ Sci 4, 4332-4339, (2011).

27.- S. I. Mussatto, M. Fernandes, A. M. F Milagres, I. C. Roberto, Enzyme Microb Tech 43, 124-129, (2008).

28.- M. S. Tunc and A. van Heiningen, Ind Eng Chem Res 47, 7031-7037, (2008)

29.- W. C. Feist, A. J. Baker, H. Tarkow, J Anim Sci 30, 832-835, (1970).

30.- R. A. Silverstein, Y. Chen, R. R. Sharma-Shivappa, M. D. Boyette, J. Osborne, Bioresource Technol 98, 3000-3011, (2007).

31.- H. Sixta, Pulp properties and applications. Handbook of pulp: 1009-1067, (2006).

32.- A. Ferraz, J. Baeza, J. Rodriguez, J. Freer, Bioresource Technol 74, 201$212,(2000)$ 
33.- O. Faix, D. Meier, I. Fortmann, Holz Roh Werkst. 48, 351-354, (1990). 34.- J. Ralph, R. D. Hatfield, J Agr Food Chem 39, 1426-1437, (1991).

35.- H. Kim, J. Ralph, T. Akiyama, Bioenergy Res 1, 55-66, (2008).

36.- J. H. Grabber, Crop Sci 45, 820-831, (2005).

37.- R. A. Silverstein, Y. Chen, R. R. Sharma-Shivappa, M. D. Boyette, J. Osborne, Bioresource Technol 98, 3000-3011, (2007).

38.- B. S. Donohoe, S. R. Decker, M. P. Tucker, M. E. Himmel, T. B. Vinzant, Biotechnol Bioeng 101, 913-925, (2008).

39.- J. B. Kristensen, L. G. Thygesen, C. Felby, H. Jørgensen, T. Elder, Biotechnol Biofuels 1, 1-9, (2008).

40.- D. Yelle, J. Ralph, C. Frihart, Magn Reson Chem 46, 508 - 517, (2008).
41.- S. A. Ralph, J. Ralph, L.Landucci, NMR Database of Lignin and Cell Wall Model Compounds, http://www.dfrc.ars.usda.gov/software.htmL, (2004).

42.- R. Samuel, S. Cao, B. K. Das, F. Hu, Y. Pu, A. J. Ragauskas, RSC Adv 3, 5305-5309, (2013).

43.- G. Moxley, A. R. Gaspar, D. Higgins, H. Xu, J Ind Microbiol Biot 39, 1289-1299, (2012).

44.- J. Li, G. Henriksson, G. Gellerstedt, Bioresource Technology 98, 30613068, (2007).

45.- R. Samuel, Y. Pu, B. Raman, A. J. Ragauskas, Appl Biochem Biotech 162, 62-74, (2010).

46.- J. Zhang, M. Siika-aho, M. Tenkanen, L. Viikari, Biotech Biofuels 4, 1-10, (2011). 